\title{
Thyroid Hormone and C-Reactive Protein Serum Concentrations, Disease Severity and Discharge Outcomes of Ischemic Stroke Patients: A Dataset
}

\section{Adomas Bunevicius $^{a, b}(\bigotimes)$, Henrikas Kazlauskas ${ }^{c}$, Nijole Raskauskiene ${ }^{d}$, Vinsas Janusonis ${ }^{c}$, Robertas Bunevicius ${ }^{d}$}

a Department of Neurosurgery, Lithuanian University of Health Sciences, Eiveniu str. 2, LT-50009, Kaunas, Lithuania http://www.kaunoklinikos.It/

b Neuroscience Institute, Lithuanian University of Health Sciences, Eiveniu str. 4, LT-50009, Kaunas, Lithuania http://Ismuni./t/en/structure/medical-academy-/neuroscience-institute/

c Department of Neurology, Klaipeda University Hospital, Liepojos str. 41, 92288 Klaipeda, Lithuania http://www.kul.It/

d Behavioural Medicine Institute, Lithuanian University of Health Sciences, Vyduno al. 4, 00135 Palanga, Lithuania http://Ismuni.lt/en/structure/medical-academy-/behavioral-medicine-institute/about-institute/

\begin{abstract}
ARTICLE INFO:
RECEIVED: 06 Jul 2015

REVISED: 02 Aug 2015

ACCEPTED: 21 Aug 2015

ONLINE: 17 Sep 2015
\end{abstract}

KEYWORDS:

Ischemic stroke

Thyroid hormones

C-reactive protein

Outcomes

Neuroprotection

\begin{abstract}
A B STRACT
Ischemic stroke remains a serious public health problem, associated with significant mortality and morbidity. Accurate and timely prognostication of functional and patient-oriented outcomes of stroke victims is important for improving patient outcomes and for optimized use of healthcare resources. A growing body of evidence suggests that the Hypothalamic-Pituitary-Thyroid axis hormones can exert neuro-protective properties under ischemic conditions and can be employed for outcome prediction in severely ill patients, including stroke victims. The goal of the present study was to investigate the association of the HPT-axis and C-reactive protein (CRP) serum concentrations with clinical stroke severity and with functional and cognitive discharge outcomes. Here we present a dataset from prospective observational cohort study of 88 acute ischemic stroke patient admitted within 24 hours after stroke symptom onset and without thyroid gland disorders. All patients received treatment according to the existing guidelines. The dataset includes socio-demographic and clinical characteristics, clinical stroke severity assessment (Scandinavian Stroke Scale), serum concentrations of tri-iodothyronine, thyroxin, thyroid stimulating hormone and CRP that were evaluated within 24 hours after hospital admission. Functional outcome (modified Rankin scale) and cognitive outcome (Mini Mental State Examination) assessments were performed at hospital discharge.
\end{abstract}




\section{Overview}

Stroke is among the leading causes of death and remains an important cause of handicap worldwide. ${ }^{1,2}$ Ischemic stroke is the most common type of stroke and is followed by intracerebral haemorrhage and subarachnoid haemorrhage due to ruptured intracranial artery aneurysms. ${ }^{2}$ Accurate and early prognostication of disease course and outcomes is critical for identification of stroke victims who could benefit from targeted therapies in order to enhance recovery from stroke. However, prognostication of stroke outcomes remains challenging. ${ }^{3,4}$ Currently, ischemic stroke symptom severity is evaluated using standardized clinical stroke symptom severity rating scales, patients' age and extent on brain damage on routinely available imaging modalities, such as head computed tomography or magnetic resonance imaging. These are the most commonly employed clinical variables to predict immediate and long-term ischemic stroke patient outcomes. ${ }^{4,5}$ However, prognostic value of commonly evaluated clinical parameters remains insufficient and there remains a constant need for research efforts directed towards development of novel blood and imaging biomarkers that could potentially improve diagnostic accuracy of current outcome prognostication systems. ${ }^{4,6,7}$

Towards this end, extensive research suggests that serum concentrations of the HypothalamicPituitary-Thyroid (HPT) axis hormones are altered in patients suffering from severe somatic illnesses, including stroke. ${ }^{8-10}$ The thyroid gland hormones (tri-iodothyronine, or T3, and thyroxin, or T4) are produced and secreted in response to stimulation by the thyroid-stimulating hormone (TSH), which is produced by the pituitary gland, and its secretion is regulated by the hypothalamic thyrotropinreleasing hormone (TRH) and via the negative feedback by the thyroid gland hormones. ${ }^{11-13}$ Thyroid hormones undergo complex metabolism in peripheral tissues, including brain, and exert numerous genomic and non-genomic actions. Recent review papers provide detailed examination of the HPT-axis function under normal conditions and in disease states. ${ }^{14-16}$ It is well described that normal functioning of the HPT-axis is commonly disturbed in severely ill patients and is associated with development of the Low-T3 syndrome (or non-thyroidal illness syndrome) that is coined as reduced serum T3 concentrations together with normal TSH concentrations in the absence of overt thyroid disorder. ${ }^{9}$ Reduced peripheral tissue T4 to T3 deiodination, decreased hypothalamic TRH and pi- tuitary TSH release, as well as impaired T4/T3 uptake by cells are among important biological mechanisms underlying the development of the Low T3 syndrome. ${ }^{9}$

A steadily growing body of evidence in animal models strongly suggests that thyroid gland hormones are neuro-protective in the context of ischemic brain damage and lower serum concentrations of T3 and T4 (as in the low T3 syndrome) are associated with greater mortality and handicap rate of stroke victims. ${ }^{8,17,18}$ Neuro-protective actions of thyroid hormones in stroke setting were recently reviewed. ${ }^{8}$ For example, in a recent study Genovese with colleagues investigated neuro-protective role of the T4 in the middle cerebral artery occlusion (MCAO) rat model and have found that, relative to placebo, T4 administration prior to stroke was associated with smaller brain infarction volume and lesser neurological damage. ${ }^{19}$ The same study has shown that T4 administration was associated with suppression of gliosis, neuro-inflammation and apoptosis, that was accompanied by increased neurotropic factor expression, providing insight into biological mechanisms underlying neuro-protective effects of thyroid gland hormones. ${ }^{19}$ Abundant clinical studies in ischemic stroke patients have documented that lower serum concentrations of T4 and T3 during the acute phase of stroke was associated with greater clinical stroke severity, more brain damage as evident on neuroimaging studies, as well as greater mortality and handicap rates. ${ }^{17,18,20,21}$ For example, a study from Poland in 387 ischemic stroke patients has shown that lower T3 serum concentration on admission was associated with greater neurological impairment on admission and ventricular system compression on admission brain computed tomography scan, and with greater disability and mortality rates at 30 -days and at 1 -year. ${ }^{17}$ These findings suggest that low T3 syndrome can be an important prognostic biomarker of functional outcomes in ischemic stroke patients. However, studies investigating the importance of thyroid hormone concentrations for discharge destination and cognitive outcomes remain sparse.

Ischemic stroke is associated with systemic inflammatory response and increased serum concentrations of inflammatory biomarkers, such as C-reactive protein (CRP). Greater CRP concentrations have been documented as a reliable biomarker of poor prognosis of patients with ischemic stroke. ${ }^{7,22,23}$ For example, a study in 561 ischemic stroke patients has demonstrated that patients with CRP concentrations of $\geq 7 \mathrm{mg} / \mathrm{L}$ within 12 hours of symptom onset had increased risk of 
poor functional outcomes and death at 3 months, relative to patients with CRP concentrations of $<7$ $\mathrm{mg} / \mathrm{L}^{23}$ Furthermore, in the same study risk for poor outcomes increased with increasing CRP concentrations, suggesting linear association between inflammatory response and poor outcomes. Inflammatory response can interfere with normal functioning of the HPT-axis. It has been demonstrated that inflammatory cytokines can contribute towards reduction of serum T3 concentrations by inhibition of central drive of the HPTaxis and by interfering with normal functioning of the 5 -deiodinase enzymes that are mainly responsible for T4 to T3 conversion in peripheral tissues and T3 tissue availability. ${ }^{24-26}$

The goal of the present study was to evaluate the association of the HPT-axis hormone serum concentrations with clinical stroke severity and with functional and cognitive outcomes at discharge in consecutive sample of patients diagnosed with ischemic stroke.

\section{Method}

\section{Patients}

Consecutive patients diagnosed with ischemic stroke based on clinical presentation and imaging results and admitted for treatment at the stroke unit of the Klaipeda University Hospital, Klaipeda, Lithuania, in a period from July 2007 until December $\mathbf{2 0 1 0}$ were considered for this prospective observational cohort study. Patients were considered for the study if they met the following inclusion criteria:

- Diagnosis of ischemic stroke based on clinical presentation and head CT scan results

- Admission to the stroke unit within 24 hours of symptom onset

- Age of 18 years or older

- Signed informed consent form.

The study exclusion criteria covered:

- Documented thyroid or pituitary gland disorder

- Autoimmune thyroid gland disorder with serum antibody against thyroid peroxidase titer of $\geq 60 \mathrm{U} / \mathrm{mL}$

- Current use of thyroid medication or amiodarone

- Pregnant or nursing

- Inability to comprehend the study assignments or sign informed consent due to severe neurological impairment or inability to communicate in Lithuanian
- Other type stroke (haemorrhagic stroke or aneurysmal subarachnoid haemorrhage) on initial admission head CT scan.

Eighty-eight patients have met the study criteria and comprised the study sample. Cognitive and functional outcomes at discharge were evaluated in 69 (78\%) and 79 (90\%) patients, respectively.

\section{Procedures}

The study and its consent procedures were approved by the Lithuanian Bioethics Committee and conformed to the principles outlined in the Declaration of Helsinki. All patients gave written informed consent prior to inclusion in the study.

On admission, all patients with suspected stroke underwent routine non-contrast head CT scan to rule out haemorrhagic stroke or subarachnoid haemorrhage or other causes of neurological deterioration. All patients received standard treatment based on clinical need, including intravenous thrombolysis that was considered for all eligible patients according to standard of care.

Patients meeting the study criteria were approached and evaluated by the study neurologist for:

- Demographic data (age and gender)

- Clinical stroke severity (Scandinavian Stroke Scale or $\mathrm{SSS}^{27}$ )

- Currently used medication

- Vascular risk factors, including cigarette smoking, histories of hypertension, diabetes mellitus, atrial fibrillation and coronary artery disease

- Functional status before stroke (modified Rankin Scale or $\mathrm{mRS}^{28}$ )

- Stroke etiology (TOAST classification ${ }^{29}$ )

- Stroke localization was defined based on clinical data as left or right anterior carotid artery territory or as basilar artery territory stroke.

Within 24 hours after admission in the stroke unit blood samples were drawn from an antecubital vein at about 8 am before breakfast for evaluation of the HPT-axis hormone and CRP serum concentrations. Blood samples were centrifuged and serum was stored frozen at $-40^{\circ} \mathrm{C}$. After the study completion, serum samples from all study patients were analysed in a single batch for serum concentrations of free T3, free T4, TSH and antiTPO using the radio-immunoassay method (Cobas E411 analyzer, Roche Diagnostics, UK). Normal free T3 concentrations range from 3.9 to 6.7 $\mathrm{pmol} / \mathrm{l}$; free T4, from 12 to $22 \mathrm{pmol} / \mathrm{l}$; and TSH, from 0.27 to $4.2 \mathrm{mIU} / \mathrm{I}$. Serum CRP concentrations 
were analysed using the Abbott Architect c8000 clinical chemistry analyser (Abbott, USA). Normal CRP values are $\leq 5 \mathrm{mg} / \mathrm{l}$.

At discharge from the stroke unit, the study patients were evaluated for functional outcomes using the mRS scale ${ }^{28}$ and for cognitive outcome using the Mini Mental State Examination (or MMSE). ${ }^{30}$

\section{Stroke severity and outcome measures}

Admission clinical stroke severity was determined by the study neurologist by the means of the SSS. ${ }^{27}$ The SSS is composed of nine domains that include assessment of level of consciousness, aphasia, eye movement, motor strength in arms, hands and legs in the affected side, gait disturbance, orientation, speech and facial palsy. Clinical severity of each symptom included in the SSS is rated separately. Total score on the SSS ranges from 0 to 58. Lower total SSS score indicates greater clinical stroke severity.

Functional status before stroke and functional stroke outcome at discharge were determined with the mRS scale. ${ }^{28}$ The mRS is a 7-point physician rating scale that was designed to evaluate global disability, with possible outcomes ranging from "No symptoms at all" (mRS score of 0 ) to "Dead" (mRS score of 6).

Cognitive outcome at discharge was determined using the MMSE. ${ }^{30}$ The MMSE is a brief assessment tool that evaluates level of cognitive functioning across orientation, registration, attention and calculation, recall, language, repetition, complex commands domains. Possible total scores on the MMSE range from 0 to 30 and greater score indicates better cognitive functioning.

\section{Use and potential reuse of the dataset}

Variables included in the dataset are presented in Table 1 . The study findings were presented in international meetings $s^{31,32}$ and were used for original research publication investigating the associations of free T3, free T4, TSH and CRP serum concentrations with admission stroke severity and with clinical and functional outcomes at discharge. ${ }^{33}$ Clinical data, included in the present dataset, were also used for publication analysing the importance of $\mathrm{N}$-terminal pro-B-type natriuretic peptide, high sensitivity CRP and inteleukin- 6 for prognostication of stroke patients. ${ }^{7}$ Briefly, we have found that higher admission CRP concentrations were associated with worse discharge functional outcomes, and lower admission free T3 concentration - with worse discharge cognitive outcomes. These associations were independent
Table 1. Data records - description of variables included in the dataset.

\begin{tabular}{|c|c|}
\hline Variable categories & Variable (Coding) \\
\hline Age & Years \\
\hline Gender & Male (1) or female (2) \\
\hline Systolic blood pressure & $\mathrm{mmHg}$ \\
\hline Diastolic blood pressure & $\mathrm{mmHg}$ \\
\hline Current aspirin use & No (1) or Yes (2) \\
\hline Stroke territory & $\begin{array}{l}\text { Left carotid artery (1) or Right } \\
\text { carotid artery (2) or Basilar ar- } \\
\text { tery (3) or Unknown (4) }\end{array}$ \\
\hline Stroke aetiology ${ }^{A}$ & $\begin{array}{l}\text { Atherothrombotic (1) or Cardi- } \\
\text { oembolic ( } 2 \text { ) or Unknown (3) or } \\
\text { Other (4) }\end{array}$ \\
\hline \multicolumn{2}{|l|}{ Vascular risk factors } \\
\hline Arterial hypertension & No (1) or Yes (2) \\
\hline Atrial fibrillation & No (1) or Yes (2) \\
\hline Smoking & No (1) or Yes (2) \\
\hline Diabetes mellitus & No (1) or Yes (2) \\
\hline Coronary artery disease & No (1) or Yes (2) \\
\hline Stroke & No (1) or Yes (2) \\
\hline Thrombolysis & No (1) or Yes (2) \\
\hline Hospital stay & Days \\
\hline $\begin{array}{l}\text { Modified Rankin scale } \\
\text { before stroke }\end{array}$ & Score \\
\hline $\begin{array}{l}\text { Scandinavian stroke } \\
\text { scale }\end{array}$ & Score \\
\hline
\end{tabular}

Serum concentrations of Hypothalamic-Pituitary-Thyroid axis hormones and C-reactive protein

\begin{tabular}{ll}
\hline $\begin{array}{l}\text { Free tri-iodothyronine } \\
\text { serum concentration }\end{array}$ & $\mathrm{pmol} / \mathrm{l}$ \\
$\begin{array}{l}\text { Free thyroxin serum } \\
\text { concentration }\end{array}$ & $\mathrm{pmol} / \mathrm{l}$ \\
$\begin{array}{l}\text { Thyroid stimulating } \\
\text { hormone serum con- } \\
\text { centration }\end{array}$ \\
$\begin{array}{l}\text { C-reactive protein se- } \\
\text { rum concentration }\end{array}$ \\
\hline $\begin{array}{l}\text { Discharge outcomes } \\
\text { Modified Rankin scale }\end{array}$ \\
$\begin{array}{l}\text { at discharge } \\
\text { Mini mental state ex- } \\
\text { amination at discharge }\end{array}$ \\
\hline Score \\
\hline
\end{tabular}

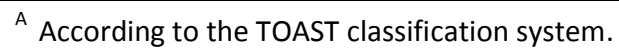

from patients' age, gender, clinical stroke severity and functional status before stroke, and suggest 
that CRP and free T3 can be important biomarkers in stroke patients.

The present dataset can be used for computational modelling studies exploring interaction between inflammatory system response and HPTaxis activity in the early phase of stroke and clinical significance of such interaction for patient outcomes. Better understanding of inflammatory and endocrine system response in acute phase of ischemic stroke can facilitate the definition of novel targets for treatment interventions that can translate into improved patient outcomes.

\section{Data Files}

The data described in this paper is presented in an openly accessible spreadsheet: "01204_ Stroke_Bunevicius.xIsx".

The file is available also in the Open Document Spreadsheet format.

\section{References}

${ }^{1}$ The World Health Organization. The world health report 2007: a safer future: global public health security in the 21st century. Geneva, Switzerland: WHO Press; 2007. Available from: http://www.who.int/whr/2007/en/.

${ }^{2}$ Go AS, Mozaffarian D, Roger VL, Benjamin EJ, Berry JD, Blaha MJ, et al. Executive summary: heart disease and stroke statistics--2014 update: a report from the American Heart Association. Circulation 2014; 129: 399-410. DOI: 10.1161/01. cir.0000442015.53336.12.

${ }^{3}$ Elkind MS. Inflammatory mechanisms of stroke. Stroke 2010; 41: S3-8. DOI: 10.1161/STROKEAHA.110.594945.

${ }^{4}$ Rothstein L, Jickling GC. Ischemic stroke biomarkers in blood. Biomark Med 2013; 7: 37-47. DOI: $10.2217 / \mathrm{bmm} .12 .104$.

${ }^{5}$ Jickling GC, Sharp FR. Blood biomarkers of ischemic stroke. Neurotherapeutics 2011;8:349-60. DOI: 10.1007/s13311-011-0050-4.

${ }^{6}$ Bunevicius A, Yuan $\mathrm{H}$, Lin W. The potential roles of 18F-FDG-PET in management of acute stroke patients. Biomed Res Int 2013; 2013: 634598. DOI: $10.1155 / 2013 / 634598$.

${ }^{7}$ Bunevicius A, Kazlauskas H, Raskauskiene N, Mickuviene N, Ndreu R, Corsano E, et al. Role of $\mathrm{N}$-Terminal Pro-B-Type Natriuretic Peptide, HighSensitivity C-Reactive Protein, and Inteleukin-6 in Predicting a Poor Outcome after a Stroke. Neuroimmunomodulation 2015 [E-pub ahead of print]. DOI: 10.1159/000381218.
${ }^{8}$ Bunevicius A, lervasi G, Bunevicius R. Neuroprotective actions of thyroid hormones and lowT3 syndrome as a biomarker in acute cerebrovascular disorders. Expert Rev Neurother 2015; 15: 315-26. DOI: 10.1586/14737175.2015.1013465.

9 Warner $\mathrm{MH}$, Beckett GJ. Mechanisms behind the non-thyroidal illness syndrome: an update. J Endocrinol 2010; 205: 1-13. DOI: 10.1677/JOE-090412.

${ }^{10}$ Farwell AP. Nonthyroidal illness syndrome. Curr Opin Endocrinol Diabetes Obes 2013; 20: 478-84. DOI: 10.1097/01.med.0000433069.09294. e8.

${ }^{11}$ Leonard JL, Koehrle J. Intracellular pathways of iodothyronine metabolism. Philadelphia, Pennsylvania , USA: Lippincott-Raven Publishers; 1996.

${ }^{12}$ Bunevicius R, Prange AJ, Jr. Thyroid disease and mental disorders: cause and effect or only comorbidity? Curr Opin Psychiatry 2010; 23: 363-8. DOI: 10.1097/YCO.0b013e3283387b50.

${ }^{13}$ Bianco AC, Salvatore D, Gereben B, Berry MJ, Larsen PR. Biochemistry, cellular and molecular biology, and physiological roles of the iodothyronine selenodeiodinases. Endocrine reviews 2002; 23: 38-89. PMID: 11844744.

${ }^{14}$ Lin HY, Davis FB, Luidens MK, Mousa SA, Cao $\mathrm{JH}$, Zhou $\mathrm{M}$, et al. Molecular basis for certain neuroprotective effects of thyroid hormone. Front Mol Neurosci 2011; 4: 29. DOI: 10.3389/fnmol. 2011.00029.

${ }^{15}$ Davis PJ, Leonard JL, Davis FB. Mechanisms of nongenomic actions of thyroid hormone. Front Neuroendocrinol. 2008; 29: 211-8. PMID: 17983645.

${ }^{16}$ Leonard JK. Intracellular pathways of iodothyronine metabolism. In: Werner I, ed. The thyroid: A fundamental and clinical text, 7th ed. Philadelphia: Lippincott-Raven Publishers; 1996:136-73.

${ }^{17}$ Ambrosius W, Kazmierski R, Gupta V, Warot AW, Adamczewska-Kociałkowska D, Błazejewska $A$, et al. Low free triiodothyronine levels are related to poor prognosis in acute ischemic stroke. Exp Clin Endocrinol Diabete 2011; 119: 139-43. DOI: 10.1055/s-0030-1267918.

${ }^{18}$ Alevizaki $M$, Synetou $M$, Xynos K, Pappa T, Vemmos KN. Low triiodothyronine: a strong predictor of outcome in acute stroke patients. Eur J Clin Invest. 2007; 37: 651-7. PMID: 17635576.

${ }^{19}$ Genovese T, Impellizzeri D, Ahmad A, Cornelius C, Campolo M, Cuzzocrea S, et al. Post-ischaemic thyroid hormone treatment in a rat model of acute stroke. Brain Res. 2013; 1513: 92-102. DOI: 10.1016/j.brainres.2013.03.001. 
${ }^{20}$ Zhang Y, Meyer MA. Clinical analysis on alteration of thyroid hormones in the serum of patients with acute ischemic stroke. Stroke Res Treat. 2010. DOI: $10.4061 / 2010 / 290678$.

${ }^{21}$ Neidert S, Katan M, Schuetz P, Fluri F, Ernst A, Bingisser $\mathrm{R}$, et al. Anterior pituitary axis hormones and outcome in acute ischaemic stroke. J Intern Med. 2011; 269: 420-32. DOI: 10.1111/j.13652796.2010.02327.x.

${ }^{22}$ Di Napoli M, Schwaninger M, Cappelli R, Ceccarelli E, Di Gianfilippo G, Donati C, et al. Evaluation of $\mathrm{C}$-reactive protein measurement for assessing the risk and prognosis in ischemic stroke: a statement for health care professionals from the CRP Pooling Project members. Stroke. 2005; 36: 131629. PMID: 15879341.

${ }^{23}$ den Hertog HM, van Rossum JA, van der Worp $H B$, van Gemert HM, de Jonge R, Koudstaal PJ, et al. C-reactive protein in the very early phase of acute ischemic stroke: association with poor outcome and death. J Neurol. 2009; 256: 2003-8. DOI: 10.1007/s00415-009-5228-x.

${ }^{24}$ van der Poll T, Romijn JA, Wiersinga WM, Sauerwein HP. Tumor necrosis factor: a putative mediator of the sick euthyroid syndrome in man. J Clin Endocrinol Metab. 1990; 71: 1567-72. PMID: 2229314.

${ }^{25}$ Abo-Zenah HA, Shoeb SA, Sabry AA, Ismail HA. Relating circulating thyroid hormone concentrations to serum interleukins- 6 and -10 in association with non-thyroidal illnesses including chronic renal insufficiency. BMC Endocr Disord. 2008; 8: 1472-6823. DOI: 10.1186/1472-6823-8-1.

${ }^{26}$ Jublanc C, Bruckert E, Giral P, Chapman MJ, Leenhardt L, Carreau V, et al. Relationship of circulating C-reactive protein levels to thyroid status and cardiovascular risk in hyperlipidemic euthyroid subjects: low free thyroxine is associated with elevated hsCRP. Atherosclerosis. 2004; 172: 7-11. PMID: 14709351.

${ }^{27}$ Lindenstrom E, Boysen G, Christiansen LW, Hansen BR, Nielsen P.W. Reliability of Scandinavian Neurological Stroke Cerebrovasc Dis. 1991; 1: 103-7, DOI: 10.1159/000108825.

${ }^{28}$ Bonita R, Beaglehole R. Recovery of motor function after stroke. Stroke. 1988; 19: 1497-500. PMID: 3201508.

${ }^{29}$ Adams HP, Bendixen BH, Kappelle $L$, Biller J, Love BB, Gordon DL, et al. Classification of subtype of acute ischemic stroke. Definitions for use in a multicenter clinical trial. TOAST. Trial of Org 10172 in Acute Stroke Treatment. Stroke. 1993; 24: 3541. PMID: 7678184.

${ }^{30}$ Folstein MF, Folstein SE, McHugh PR. Minimental state. A practical method for grading the cognitive state of patients for the clinician. J Psych Res 1975; 12: 189-98. PMID: 1202204.

${ }^{31}$ Kazlauskas $\mathrm{H}$, Bunevicius A, Raskauskiene $\mathrm{N}$, Anskoliene $A$, Radziuviene $R$, Janusonis $V$, et al. Cognitive Outcomes of Acute Ischemic Stroke Patients: Association with Concentrations of Thyroid Axis Hormones and C-Reactive Protein. Annals of Neurology 2012; 72(Suppl. 16): S4-S4.

${ }^{32}$ Kazlauskas $\mathrm{H}$, Bunevicius A , Raskauskienè N, Radziuvienè R, Anskoliene A, Janusonis $V$, et al. Functional outcome of acute ischemic stroke patients: association with concentrations of thyroid hormones and C-reactive protein. European Journal of Neurology, 2012; Suppl 1: 152.

${ }^{33}$ Bunevicius A, Kazlauskas $\mathrm{H}$, Raskauskiene $\mathrm{N}$, Janusonis $V$, Bunevicius R. Ischemic stroke functional outcomes are independently associated with C-reactive protein concentrations and cognitive outcomes with triiodothyronine concentrations: a pilot study. Endocrine 2014; 45: 213-20. DOI: 10.1007/s12020-013-9958-2. 